\title{
Modification of MOR by desilication treatments: Structural, textural and acidic characterization
}

\author{
Viviana Paixão ${ }^{\mathrm{a}}$, Ana P. Carvalho ${ }^{\mathrm{b}}$, João Rocha ${ }^{\mathrm{c}}$, Auguste Fernandes ${ }^{\mathrm{d}}$, Angela Martins ${ }^{\mathrm{a}, *}$ \\ a Departamento de Engenharia Química and CIEQB, Instituto Superior de Engenharia de Lisboa, Rua Conselheiro Emídio Navarro, 1, 1959-007 Lisboa, Portugal \\ ${ }^{\mathrm{b}}$ Departamento de Química e Bioquímica, CQB, Faculdade de Ciências da Universidade de Lisboa, Campo Grande C8, 1749-016 Lisboa, Portugal \\ ${ }^{\mathrm{C}}$ Departamento de Química and CICECO, Universidade de Aveiro, 3810-193 Aveiro, Portugal \\ ${ }^{\mathrm{d}}$ Instituto de Biotecnologia e Bioengenharia, Instituto Superior Técnico, Av. Rovisco Pais, 1049-001 Lisboa, Portugal
}

\section{A R T I C L E I N F O}

\section{Article history:}

Received 8 December 2009

Received in revised form 18 January 2010

Accepted 19 January 2010

Available online 28 January 2010

\section{Keywords:}

Mesoporous mordenite

Desilication

FTIR

${ }^{27} \mathrm{Al}$ and ${ }^{29} \mathrm{Si}$ MAS-NMR

Acidity

\begin{abstract}
A B S T R A C T
The effect of several desilication experimental parameters (base concentration, temperature and time) on the characteristics of MOR zeolite was studied. The samples were characterized by X-ray diffraction, ${ }^{27} \mathrm{Al}$ and ${ }^{29}$ Si MAS-NMR, chemical analysis, and FTIR (framework vibration region). The textural characterization was made by $\mathrm{N}_{2}$ adsorption and the acidity was evaluated by pyridine adsorption followed by FTIR and by the catalytic model reaction of $n$-heptane cracking. The alkaline treatments promoted the $\mathrm{Si}$ extraction from the zeolite framework, without considerable loss of crystallinity and, as it was envisaged, an important increase of the mesoporous structure was attained. A linear correlation between the number of framework Si per unit cell, $N_{\mathrm{Si}}$, and the asymmetric stretching wavenumber, $v_{1}$, was observed. The acidity characterization shows that the desilicated samples exhibit practically the same acid properties than the parent HMOR zeolite. The optimum desilication conditions were those used to obtain sample $\mathrm{M} / 0.2 / 85 / 2$, i.e., sample treated with $0.2 \mathrm{M} \mathrm{NaOH}$ solution at $85^{\circ} \mathrm{C}$ for $2 \mathrm{~h}$.
\end{abstract}

() 2010 Elsevier Inc. All rights reserved.

\section{Introduction}

Zeolites are crystalline aluminosilicates with a unique combination of properties, such as, high surface area, well-defined microporosity, high thermal stability and intrinsic acidity. These materials have been widely used in catalysis as well as in separation and purification fields [1].

The modification of the purely microporous character of zeolites is an important aspect that can be explored. In fact, the pure microporous character of zeolites often imposes diffusion limitations due to restricted access to the active sites, especially when bulky reaction intermediate species are involved. This is the case of some applications in the petroleum, petrochemical and fine chemical industries.

In order to enhance the accessibility and molecular transport, two different approaches can be adopted. One of the routes is shortening the microporous path length. This can be achieved by altering the synthesis protocols in order to obtain zeolite nanocrystals [2]. The second approach aims to increase the diffusion inside the pores. Several solutions have been proposed like the synthesis of wide-pore and large-cavity zeolites [3], delamination of zeolites [4] and composites of zeolites and mesoporous materials [5].

\footnotetext{
* Corresponding author. Tel.: +351 218317000; fax: +351218317001.

E-mail address: amartins@deq.isel.ipl.pt (A. Martins).
}

An alternative approach, involving only post-synthesis procedures is the dealumination, traditionally performed in steam or acidic medium [6-8]. Although dealumination has proven to generate additional mesoporosity, it affects also the acidic properties of the zeolite structure, due to the extraction of aluminium from the framework. Hence, the facilitated transport provided by the introduction of mesoporosity may be partially cancelled out by the reduction of the acid sites density [9]. Another option to create mesoporosity in zeolites was first introduced by Ogura et al. in 2000 [10] in a process called desilication which consists of a controlled extraction of silicon from the framework in alkaline medium. This treatment has resulted in a promising methodology to produce extended mesoporosity in zeolites crystals, without impacting on the acidity [11]. In recent years, several publications on this subject have emerged, especially focused on MFI type zeolite, for which detailed studies of the effect of the experimental parameters on the mesoporosity development have been made [11-14].

Mordenite (MOR) is a member of the large pore zeolite family. It consists of a 12-membered ring (MR) system of pore channels of $0.67 \times 0.70 \mathrm{~nm}$ interconnected by 8 -MR pores $0.34 \times 0.48 \mathrm{~nm}$. Due to the dimensions of the 8-MR channels, which are too small to allow the diffusion of most molecules, this zeolite is considered a one-dimensional pore system inducing an unidirectional diffusion [15]. Nevertheless, since mordenite has an excellent mechanic and thermal stability it has a wide-range of industrial applications 
in processes such as alkylation [16] and short-chain paraffin hydroisomerization [17]. In hydroisomerization reactions, where a metal function is present, diffusional limitations have been referred by some authors especially when low metal dispersions are obtained. According to some authors $[18,19]$ the catalytic reactions take place only at the pore mouths, thus a large fraction of the active sites is inaccessible. In this sense, the desilication treatments open new perspectives since the presence of mesoporosity in MOR would minimize this drawback.

In this work we present a detailed study of the influence of several experimental parameters $(\mathrm{NaOH}$ concentration, temperature and time) on the structural, textural and acidic properties of MOR zeolite. In fact, to our best knowledge, although some studies were already made $[20,21]$, no systematic evaluation of the impact of the desilication conditions on the properties of this zeolitic structure is available.

\section{Experimental}

\subsection{Parent material}

The starting material used was a mordenite structure ( $\mathrm{NH}_{4} \mathrm{MOR}$ ) supplied by Zeolyst (CBV21A; lot. 2200-83), that according with the technical report has a $\mathrm{SiO}_{2} / \mathrm{Al}_{2} \mathrm{O}_{3}=20$. To obtain the protonic form (HMOR) the sample was calcined under dry air $\left(6 \mathrm{dm}^{3} \mathrm{~h}^{-1} \mathrm{~g}^{-1}\right)$ at $500{ }^{\circ} \mathrm{C}$ for $3 \mathrm{~h}$.

\subsection{Alkaline treatment of HMOR zeolite}

The alkaline treatments were carried out using $\mathrm{NaOH}$ as desilicating agent and following the experimental procedure reported in the literature [20]. Briefly, HMOR was stirred in $\mathrm{NaOH}$ (Merck, p.a.) solution using a proportion of $330 \mathrm{mg} / 10 \mathrm{~cm}^{3}$. The concentration range used was $0.1-1.0 \mathrm{M}$ and the treatments were carried out at temperatures between 50 and $100{ }^{\circ} \mathrm{C}$, during $0.5-10 \mathrm{~h}$. After the treatment the zeolite suspension was filtered, washed thoroughly up to $\mathrm{pH} 7$ and then dried overnight at $90{ }^{\circ} \mathrm{C}$. The alkaline modified solids were converted into the correspondent protonic form by three consecutives exchanges with $1 \mathrm{M}, \mathrm{NH}_{4} \mathrm{NO}_{3}$ (Merck, p.a.) solution using the proportion: $50 \mathrm{~cm}^{3} / \mathrm{g}$ of zeolite. The exchanges were carried out at $80^{\circ} \mathrm{C}$ for $3 \mathrm{~h}$. After a careful wash up to $\mathrm{pH} 7$ the solid was calcined under air flow $\left(6 \mathrm{dm}^{3} \mathrm{~h}^{-1} \mathrm{~g}^{-1}\right)$ at $500{ }^{\circ} \mathrm{C}$ for $3 \mathrm{~h}$.

To evaluate the influence of base concentration, temperature and time of the treatment on the physicochemical properties of the materials, three series of samples were prepared. The treated samples will be designated according with the expression: $\mathrm{M} /$ $\mathrm{NaOH}$ conc. $(\mathrm{M}) /$ temperature $\left({ }^{\circ} \mathrm{C}\right) /$ time $(\mathrm{h})$.

\subsection{Physicochemical characterization}

The structural characterization of the parent and modified samples was made from X-ray powder diffraction (XRD) patterns that were obtained at room temperature on a Philips PX-1730 with automatic data acquisition (APD Phillips (v3.6B) software), using $\mathrm{CuK} \alpha$ radiation as incident beam. Diffractograms were obtained by continuous scanning from $5^{\circ}$ to $40^{\circ} 2 \theta$, with a step size of $0.02^{\circ} 2 \theta$ and a time per step of $0.4 \mathrm{~s}$.

Infrared spectra in the framework vibrations range (1400$400 \mathrm{~cm}^{-1}$ ) were recorded at room temperature on a Nicolet 6700 FTIR spectrometer ( 60 scans, resolution $4 \mathrm{~cm}^{-1}$ ). The samples were analysed in the form of $\mathrm{KBr}$ supported pellets.

${ }^{27} \mathrm{Al}$ and ${ }^{29} \mathrm{Si}$ MAS-NMR spectra were recorded on a Bruker DSX $400(\mathrm{~B} 0=9.4 \mathrm{~T})$ at, respectively, 104.2 and $79.5 \mathrm{MHz}$, using $9^{\circ}$ and $45^{\circ} \mathrm{rf}$ pulses, $1 \mathrm{~s}$ and $60 \mathrm{~s}$ recycle delays and MAS rates of 14 and
$5 \mathrm{kHz}$. Chemical shifts are quoted in ppm from, respectively, $\mathrm{Al}\left(\mathrm{H}_{2} \mathrm{O}\right)_{6}^{3+}$ and tetramethylsilane (TMS).

The global Si/Al was determined by ICP (ICP-AES Horiba JobinYvon mod. Ultima). The samples were dissolved using the following protocol: $20 \mathrm{mg}$ of solid previously dried at $100{ }^{\circ} \mathrm{C}$ was made to react with $2 \mathrm{~cm}^{3}$ of aqua regia and $3 \mathrm{~cm}^{3}$ of $\mathrm{HF}$ (48\%) for $2 \mathrm{~h}$ at $120^{\circ} \mathrm{C}$. After reaching room temperature the solution was mixed with about $2 \mathrm{~g}$ of boric acid and finally adjusted to a known volume with deionised water. The reaction was performed in a stainless steel autoclave equipped with a polyethylene-covered beaker.

The textural characterization of the solids was made by $\mathrm{N}_{2}$ adsorption isotherms measured in an automatic apparatus Micromeritics ASAP 2010. Before the isotherms acquisition the samples $\left(\approx 50 \mathrm{mg}\right.$ ) were outgassed for $2 \mathrm{~h}$ at $300^{\circ} \mathrm{C}$, under vacuum better than $10^{-2} \mathrm{~Pa}$.

\subsection{Acidity characterization}

The acidic properties of the samples were studied by pyridine adsorption followed by infrared spectroscopy (FTIR) and by the catalytic model reaction of $n$-heptane cracking.

For IR characterization of the hydroxyl groups and adsorbed pyridine, the zeolite samples were pressed into $16 \mathrm{~mm}$ diameter thin wafers (5-10 $\mathrm{mg} \mathrm{cm}^{-2}$ ). Before the experiments, the self-supported wafers were outgassed in situ in an IR cell at $450{ }^{\circ} \mathrm{C}$ for $2 \mathrm{~h}$ under high vacuum $\left(10^{-4} \mathrm{~Pa}\right)$. After activation, the wafers were cooled to room temperature and the initial (base) spectrum of the samples was recorded. The wafers were then exposed to pyridine vapour $\left(2.6 \times 10^{2} \mathrm{~Pa}\right)$ during $10 \mathrm{~min}$ for saturation, at ambient temperature. Then the samples were further outgassed at 150, 250, 350 and $450{ }^{\circ} \mathrm{C}$ for $30 \mathrm{~min}$. The background spectrum, recorded under identical operating conditions without sample, was always performed before each spectrum and automatically subtracted. For quantification, the base spectrum was always subtracted from the spectra obtained during pyridine thermal desorption. The band intensities were corrected from slight differences in sample weight and band areas were calculated by fitting the spectral profile with a Gaussian-Lorentzian function using IR OMNIC ${ }^{\circledR}$ software.

The model reaction of $n$-heptane cracking was performed in a continuous flow reactor at $350{ }^{\circ} \mathrm{C}$ under a total pressure of $1 \times 10^{5} \mathrm{~Pa}$. Before the reaction the samples were pre-treated at $500{ }^{\circ} \mathrm{C}$ in situ for $10 \mathrm{~h}$ under nitrogen flow of $36 \mathrm{dm}^{3} \mathrm{~h}^{-1} \mathrm{~g}^{-1}$. Experiments were performed for 90 min using a flow of $3 \mathrm{~cm}^{3} \mathrm{~h}^{-1}$ of $n$-heptane (molar ratio $\mathrm{N}_{2} / n-\mathrm{C}_{7}=9$ ) and WHSV $=20.5 \mathrm{~h}^{-1}$. The reaction products were analysed by an on-line gas chromatograph Hewlett-Packard 6890 series with a flame ionisation detector, using a capillary column PLOT- $\mathrm{Al}_{2} \mathrm{O}_{3} / \mathrm{KCl}$.

\section{Results and discussion}

\subsection{Physicochemical characterization}

The powder XRD patterns of the alkaline treated samples are shown in Fig. 1, for the series where the effect of the treatment time was investigated. As it can be seen, the long-range crystal ordering is maintained upon alkaline treatment since no important changes in peaks position are observed. On the other hand, we can conclude that the desilication promotes some loss of crystallinity, reflected by the decrease in the peaks intensity that became more pronounced as the severity of the treatment increases. To quantify this structural modification, the values of the degree of crystallinity, $C_{\mathrm{XRD}}$, of the treated samples were evaluated by the ratio between the areas of all the diffraction peaks of the samples and of the starting protonic structure, the latter chosen as reference. Peaks integration was made using "Peak Fit" software. The results 


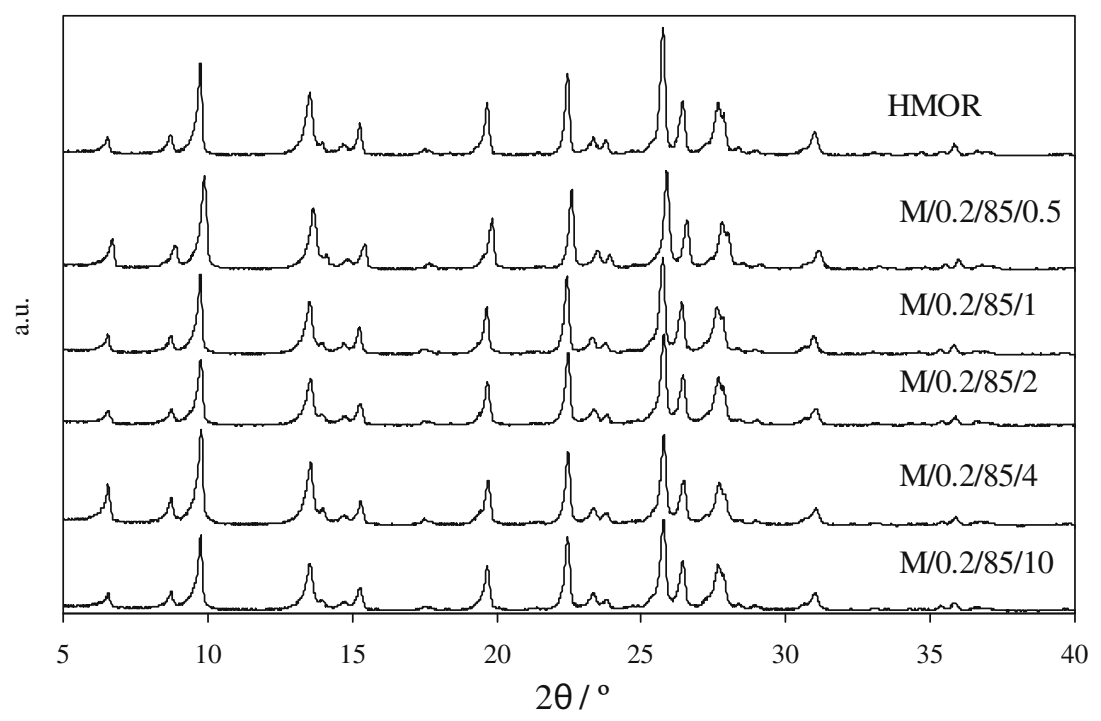

Fig. 1. X-ray diffraction patterns of HMOR and indicated alkaline treated samples.

Table 1

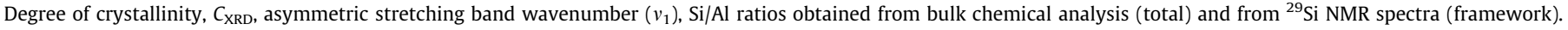

\begin{tabular}{|c|c|c|c|c|}
\hline Sample & $C_{\mathrm{XRD}}(\%)$ & $v_{1}\left(\mathrm{~cm}^{-1}\right)$ & $\mathrm{Si} / \mathrm{Al}_{\text {total }}$ & $\mathrm{Si} / \mathrm{Al}_{\text {framework }}$ \\
\hline HMOR & 100 & 1083.1 & 9.5 & 11.1 \\
\hline $\mathrm{M} / 0.2 / 50 / 1$ & 89 & 1082.0 & - & - \\
\hline $\mathrm{M} / 0.2 / 85 / 1$ & 86 & 1081.4 & - & - \\
\hline $\mathrm{M} / 0.2 / 100 / 1$ & 75 & 1073.2 & - & - \\
\hline $\mathrm{M} / 0.2 / 85 / 0.5$ & 87 & 1082.8 & - & - \\
\hline $\mathrm{M} / 0.2 / 85 / 1$ & 86 & 1081.4 & - & - \\
\hline $\mathrm{M} / 0.2 / 85 / 2$ & 83 & 1076.3 & 8.6 & 10.1 \\
\hline $\mathrm{M} / 0.2 / 85 / 4$ & 76 & 1074.5 & - & - \\
\hline $\mathrm{M} / 0.2 / 85 / 10$ & 74 & 1070.4 & 9.1 & 10.6 \\
\hline $\mathrm{M} / 0.1 / 85 / 2$ & 86 & 1082.1 & - & - \\
\hline $\mathrm{M} / 0.2 / 85 / 2$ & 83 & 1076.3 & 8.6 & 10.1 \\
\hline $\mathrm{M} / 0.5 / 85 / 2$ & 74 & 1074.4 & - & - \\
\hline $\mathrm{M} / 1.0 / 85 / 2$ & 24 & 1070.9 & 6.5 & 9.9 \\
\hline
\end{tabular}

are quoted in Table 1 and show that, as expected, the increase of the severity of any of the experimental parameters results in a decrease of the $C_{\mathrm{XRD}}$ values. Nevertheless, the decrease is less pronounced for temperature, duration and $\mathrm{NaOH}$ concentration up to, respectively, $85^{\circ} \mathrm{C}, 2 \mathrm{~h}$ and $0.2 \mathrm{M}$. Higher temperature and longer treatments led to $C_{\mathrm{XRD}}$ that are still relatively high (above $\sim 75 \%$ ). The increase of the base concentration had a more pronounced effect on the crystallinity since for sample $\mathrm{M} / 1.0 / 85 / 2$ a $C_{\mathrm{XRD}}$ value of $24 \%$ was obtained.

The ${ }^{29} \mathrm{Si} \mathrm{NMR}$ spectra of HMOR and some alkaline treated samples are presented in Fig. 2(A). Except for sample M/1.0/85/2, the lines correspondent to $\mathrm{Si}(0 \mathrm{Al})$ and $\mathrm{Si}(1 \mathrm{Al})$ at, -112 and $-107 \mathrm{ppm}$, respectively, are always present although their relative intensity changes upon desilication treatment [22]. The line correspondent to $\mathrm{Si}(1 \mathrm{Al})$ configuration becomes much more intense, confirming the Si removal. In the case of sample $M / 1.0 / 85 / 2$, that suffered a considerable loss of crystallinity, only a broad peak centered at $-107 \mathrm{ppm}$, is observed. This peak can be attributed to the presence of amorphous silica, and also to silica-alumina since the left side extends up to $-80 \mathrm{ppm}$.

The ${ }^{27} \mathrm{Al}$ NMR spectra of HMOR presented in Fig. 2(B) shows that the parent material used in this study has some non-framework 6-coordinated aluminium, denoted by the resonance at $0 \mathrm{ppm}$ [22]. This line is observed for all the alkaline treated samples, with a considerable intensity in the case of $M / 1.0 / 85 / 2$. The relation between the intensity of this line and of that at $55 \mathrm{ppm}$, corresponding to framework aluminium atoms [22], remains almost unchanged upon treatment, once again with the exception of sample $M / 1.0 / 85 / 2$. The spectrum of this sample is in fact different from all the other since a third very broad line centered at $21 \mathrm{ppm}$ is observed. This line has been found in other post-synthesis structures [23] and may be due to pentacoordinated extraframework aluminium.

The $\mathrm{Si} / \mathrm{Al}$ ratio of the tetrahedral framework $\left(\mathrm{Si} / \mathrm{Al}_{\text {framework }}\right)$ was estimated according to Ref. [22], using the integrated areas of the $\mathrm{Si}(1 \mathrm{Al})$ and $\mathrm{Si}(\mathrm{OAl})$ lines of the ${ }^{29} \mathrm{Si}$ NMR spectra and from the total $\mathrm{Si} / \mathrm{Al}$ ratio, determined by bulk chemical analysis. The results obtained are quoted in Table 1 , confirming that the alkaline treatments lead to a partial desilication of the mordenite framework. Nevertheless, the amount of Si removed from the zeolite framework was not significant. This is most likely due to the low Si/Al ratio of the starting material (about 10). In fact, the results reported in the literature for MFI zeolite show that the Si/Al ratio is an important parameter that has to be optimized to attain high desilication degrees [24]. In this study the authors proved that increasing the $\mathrm{Si} / \mathrm{Al}$ ratio of the MFI zeolite from 17 to 50 results in a great increase of the silicon extracted ( 7 times higher). To check the importance of the initial $\mathrm{Si} / \mathrm{Al}$ ratio for the desilication process of mordenite we can compare our results with those reported on Ref. [20] for a commercial mordenite with $\mathrm{Si} / \mathrm{Al}=45$, that was 
(A)

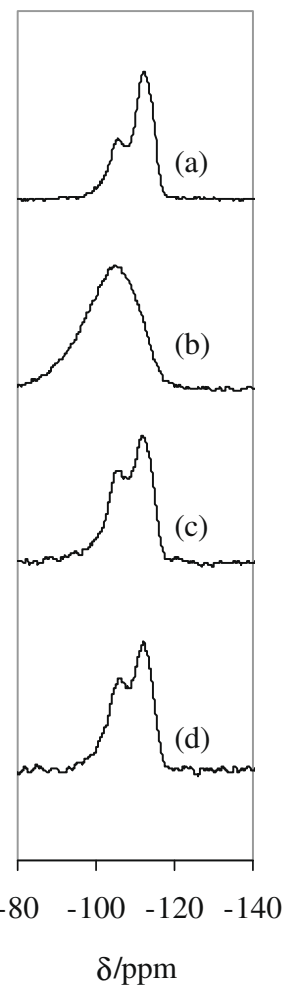

(B)

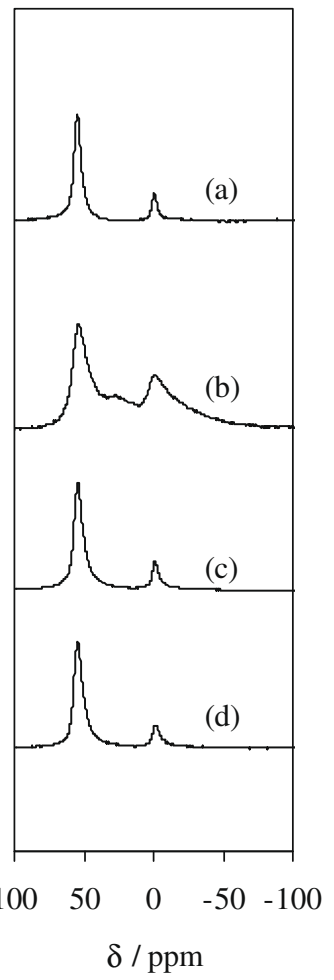

Fig. 2. ${ }^{29} \mathrm{Si}$ (A) and ${ }^{27} \mathrm{Al}$ (B) MAS-NMR spectra of (a) HMOR; (b) M/1.0/85/2; (c) M/ $0.2 / 85 / 2$; and (d) $\mathrm{M} / 0.2 / 85 / 10$.

treated under the same conditions of sample $\mathrm{M} / 0.2 / 85 / 2$. In the present study the Si/Al decreased from 9.6 to 8.6 while in the literature work the decrease was from 45 to 24 . So, it can be concluded that also for mordenite, the Si/Al ratio has a marked influence on the desilication degree.

The results of Table 1 also show a difference between the values of $\mathrm{Si} / \mathrm{Al}_{\text {total }}$ and $\mathrm{Si} / \mathrm{Al}_{\text {framework }}$ that is compatible with the presence of a fraction of extra-framework $\mathrm{Al}$ species detected in the ${ }^{27} \mathrm{Al}$ NMR spectra.

On the contrary of what is currently made in studies focussed on zeolite post-synthesis treatments, namely by dealumination processes [23], in the case of desilication treatments, the analysis of FTIR spectra in the framework vibration region has not been explored. Actually in the literature there are several empirical linear equations relating the value of asymmetric stretching band (1250$950 \mathrm{~cm}^{-1}$ ) wavenumber, $v_{1}$, and the number of aluminium per unit cell of dealuminated structures $[23,25]$. Since the shift on the framework spectra reflects the change of the relative number of $\mathrm{Al}-\mathrm{O}$ and $\mathrm{Si}-\mathrm{O}$ bonds present in the sample one would expect that, on the contrary of what is observed during dealumination, where the values of $v_{1}$ increase as the dealumination becomes more accentuated, when a desilication treatment is successfully applied the values of $v_{1}$ should decrease.

Analysing the FTIR spectra in the framework vibration region of HMOR and samples of the series where the effect of the treatment temperature was studied (Fig. 3), a shift of lattice vibration bands towards smaller wavenumbers is noticed, upon the alkaline treatment. The values of the asymmetric stretching band wavenumber, $v_{1}$, quoted in Table 1 , show that there is a continuous decrease of $v_{1}$ values with the increase of the treatment severity. The highest displacements are observed for samples treated with the more concentrated $\mathrm{NaOH}$ solution $(\mathrm{M} / 1.0 / 85 / 2)$ or for a longer time $(\mathrm{M} /$ $0.2 / 85 / 10)$. In both cases the value of $v_{1}$ presents a shift of around $12.5 \mathrm{~cm}^{-1}$ from the value presented by the parent HMOR.

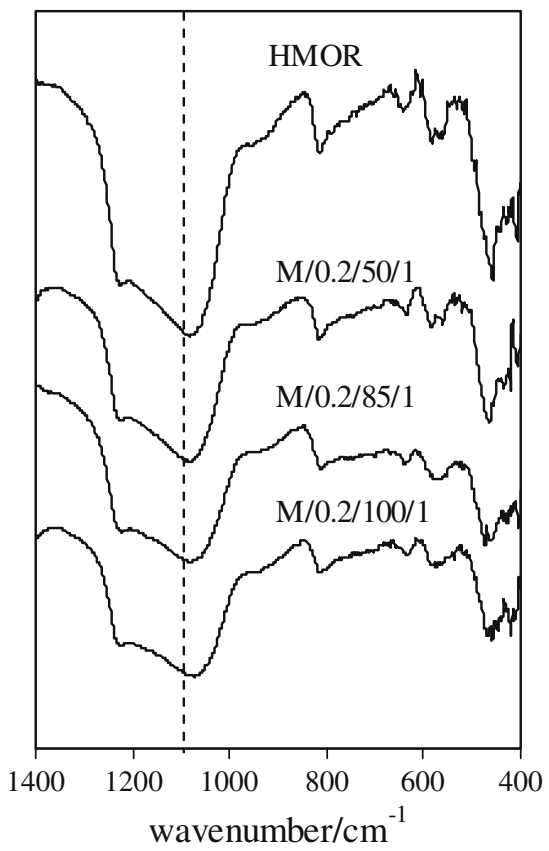

Fig. 3. FTIR spectra in the range of framework vibrations of HMOR and indicated alkaline treated samples.

The results obtained seem to point out that the evolution of the asymmetric stretching band position can be taken as an evidence of the silicon removal. To check the validity of this conclusion we plotted the values the $N_{\mathrm{Si}}$, number of framework Si atom per unit cell, of the samples characterized by NMR against the corresponding $v_{1}$ values. The plot obtained with these four samples shows a linear trend expressed by the relationship: $v_{1}\left(\mathrm{~cm}^{-1}\right)=20.2 N_{\mathrm{Si}}+193.0$. It must be taken in consideration that the range of $N_{\mathrm{Si}}$ values is narrow due to the framework stability of the starting material (see val-

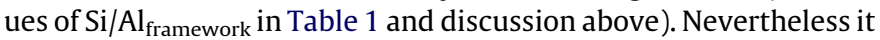
is clear that, as it is proposed in the literature for dealuminated samples, for desilicated structures an empirical correlation between the framework vibration bands wavenumbers and $N_{\mathrm{Si}}$ can also be obtained. The desilication study of mordenite structure with different $\mathrm{Si} / \mathrm{Al}$ ratios is foreseen in order to obtain values that would allow us to extend the proposed relationship to a large range of $N_{\mathrm{Si}}$.

The $\mathrm{N}_{2}$ adsorption-desorption isotherms displayed in Fig. 4(A) are representative of the curves obtained in this study. The curve of the parent structure belongs to type I in the BDDT classification [26], according to the microporous nature of the sample. Only for relative pressure near 1 there is a small upwards deviation of the plateau, pointing out some mesoporosity or external surface, resulting of the crystallites aggregation. The curves obtained for treated samples exhibit a type I with somewhat type IV character isotherms, revealing the microporosity of the samples and a considerable development of mesoporosity. The curves present a sharp knee at low relative pressures, indicating that there is no significant change on the microporous size distribution upon the treatment, and an enhancement of $\mathrm{N}_{2}$ uptake for higher $p / p^{0}$ values as well as a $\mathrm{H} 4$ type hysteresis loop, revealing the development of mesoporosity.

The adsorption data were analysed using the $\alpha_{\mathrm{S}}$ method taking as reference the isotherm determined on nonporous silica [27]. As found in studies focussed on zeolite structures [28], the $\alpha_{\text {s }}$ plots obtained revealed the presence of a very small fraction of supermicropores (width between 0.7 and $2 \mathrm{~nm}$ ), $V_{\text {super }}$, and a large volume associated with the ultramicropores (width less then $0.7 \mathrm{~nm}$ ), $V_{\text {ultra, }}$ characteristic of the mordenite framework. The microporous 

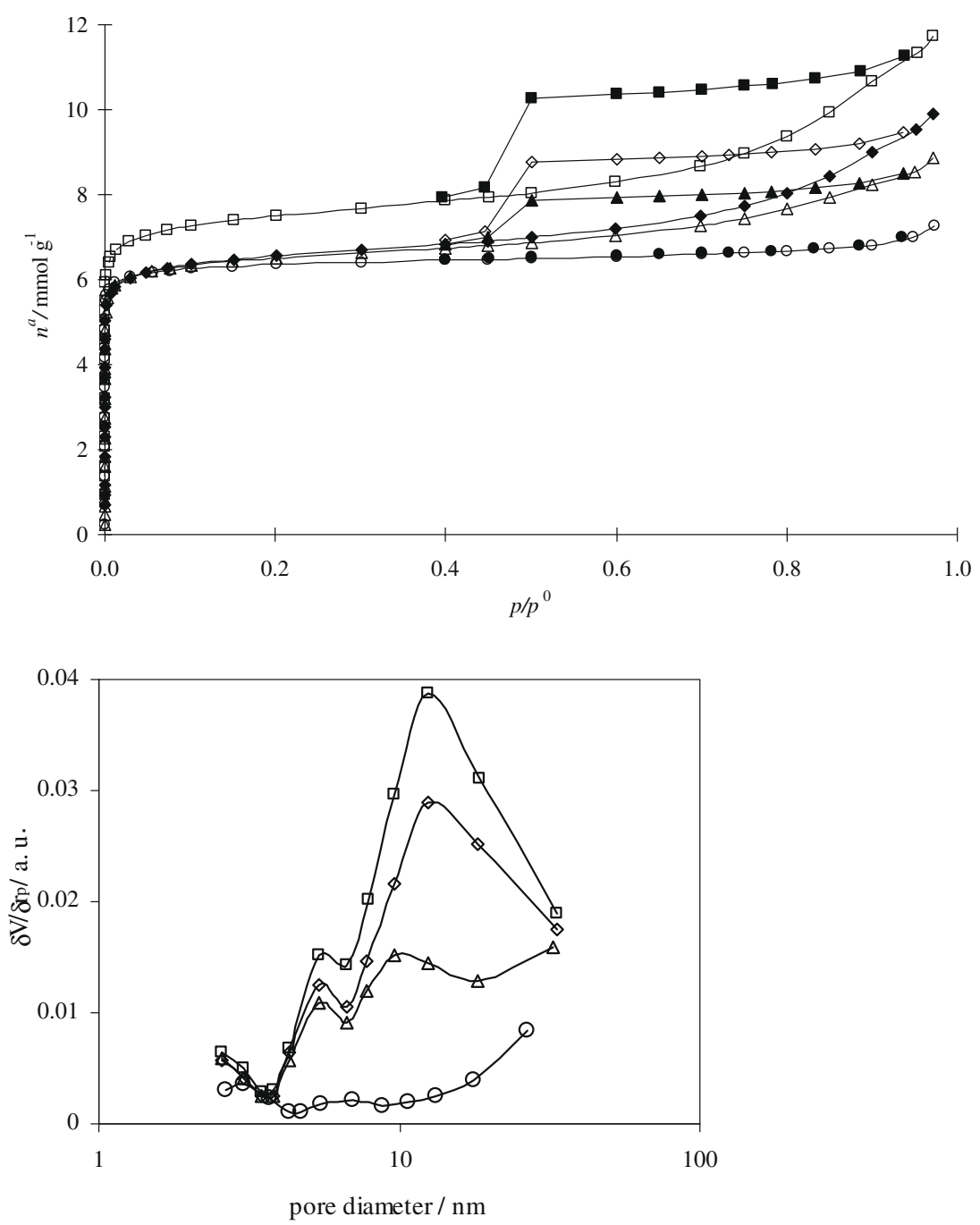

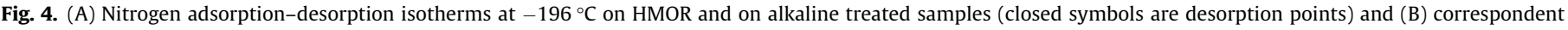
mesoporous size distribution. $\bigcirc, \mathrm{HMOR} ; \triangle \mathrm{M} / 0.2 / 85 / 0.5 ; \square, \mathrm{M} / 0.2 / 85 / 2$; and $\diamond, \mathrm{M} / 0.2 / 85 / 10$.

volume, $V_{\text {micro }}$, corresponds to $V_{\text {ultra }}+V_{\text {super }}$. The external surface area, $A_{\text {ext }}$, was computed from the slope of the linear region of the $\alpha_{s}$ plots on the multilayer region $\left(\alpha_{S}>1\right)$. The total porous volume, $V_{\text {total }}$, was estimated from the volume of $\mathrm{N}_{2}$ adsorbed at $p /$ $p^{0}=0.95$ and the mesoporous volume from the difference between $V_{\text {total }}$ and $V_{\text {micro. }}$. The results obtained from this analysis are quoted in Table 2 and show that, with the exception of the sample treated with the highest $\mathrm{NaOH}$ concentration $(\mathrm{M} / 1.0 / 85 / 2)$, the experimental procedure followed did not affect the microporosity of the samples. The values of $V_{\text {micro }}$ vary from $0.20 \mathrm{~cm}^{3} \mathrm{~g}^{-1}$, for sample HMOR, to $0.18-0.19 \mathrm{~cm}^{3} \mathrm{~g}^{-1}$ for the majority of the samples. This behaviour is in line with the results reported by other authors in studies also focussed on mordenite desilication [20,21], and are in agreement with the evolution of the crystallinity assessed by XRD, $C_{\mathrm{XRD}}$, previously discussed. On the other hand it is also clear that the alkaline treatment, on the contrary of what occurs in dealumination, do not promote the formation of larger micropores (supermicropores), since $V_{\text {super }}$ remains practically constant. An identical behaviour was found, by Groen et al. for the evolution of the microporosity of MFI upon treatment with $\mathrm{NaOH}$, based on the data of high-resolution low pressure Ar-adsorption isotherms [12].

The most important textural effect of the desilication treatment is, as it was envisaged, a substantial development of mesoporous volumes, which in the majority of the samples, is 3 or 4 times high- er than the value present by the starting HMOR. The results also show that no significant mesoporosity creation is observed when the treatments are carried out at $50{ }^{\circ} \mathrm{C}$ or with $0.1 \mathrm{M}, \mathrm{NaOH}$ solution.

To evaluate the effect of the initial Si/Al ratio on the textural characteristics of the desilicated samples, we can confront the results of sample $\mathrm{M} / 0.2 / 85 / 2$ with those of the desilicated mordenite sample reported on Ref. [20], since both were submitted to the same experimental conditions. The values show that in this study the increase of $V_{\text {meso }}$ was of almost 4 times and in Ref. [20], where a parent structure with $\mathrm{Si} / \mathrm{Al}=45$ was used, the increase of the $S_{\text {meso }}$ (mesopores surface) was about 3 times. This allows us to conclude that the initial Si/Al ratio has no significant influence on the mesoporosity development upon mordenite desilication.

The fact that no degradation of the intrinsic microporosity is observed and the considerable increase of the external surface area points out that the mesopores were created from the destruction of the framework, from the crystal outer surface towards the interior.

The mesopore size distribution was made according the Broekhoff-de Boer method, in a version simplified with the Frenkel-Halsey-Hill equation (BdB-FHH) [29]. The plots in Fig. 4(B) illustrate the results obtained, showing that the modified samples have broad mesopores size distributions. The maximum centered at 
Table 2

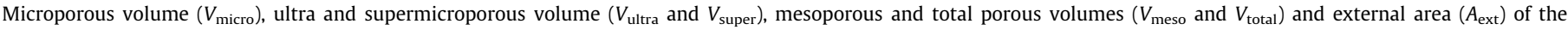
samples.

\begin{tabular}{|c|c|c|c|c|c|c|}
\hline Sample & $V_{\text {micro }}{ }^{\mathrm{a}}\left(\mathrm{cm}^{3} \mathrm{~g}^{-1}\right)$ & $V_{\text {ultra }}{ }^{\mathrm{a}}\left(\mathrm{cm}^{3} \mathrm{~g}^{-1}\right)$ & $V_{\text {super }}{ }^{\mathrm{a}}\left(\mathrm{cm}^{3} \mathrm{~g}^{-1}\right)$ & $V_{\text {total }}{ }^{\mathrm{b}}\left(\mathrm{cm}^{3} \mathrm{~g}^{-1}\right)$ & $V_{\text {meso }}{ }^{\mathrm{c}}\left(\mathrm{cm}^{3} \mathrm{~g}^{-1}\right)$ & $A_{\text {ext }}\left(\mathrm{m}^{2} \mathrm{~g}^{-1}\right)$ \\
\hline HMOR & 0.20 & 0.19 & 0.01 & 0.25 & 0.05 & 24 \\
\hline $\mathrm{M} / 0.2 / 50 / 1$ & 0.20 & 0.18 & 0.02 & 0.26 & 0.06 & 49 \\
\hline $\mathrm{M} / 0.2 / 85 / 1$ & 0.19 & 0.17 & 0.02 & 0.34 & 0.15 & 122 \\
\hline $\mathrm{M} / 0.2 / 100 / 1$ & 0.18 & 0.17 & 0.01 & 0.33 & 0.15 & 113 \\
\hline $\mathrm{M} / 0.2 / 85 / 0.5$ & 0.19 & 0.17 & 0.02 & 0.30 & 0.11 & 92 \\
\hline $\mathrm{M} / 0.2 / 85 / 1$ & 0.19 & 0.17 & 0.02 & 0.34 & 0.15 & 122 \\
\hline $\mathrm{M} / 0.2 / 85 / 2$ & 0.21 & 0.19 & 0.02 & 0.40 & 0.19 & 133 \\
\hline $\mathrm{M} / 0.2 / 85 / 4$ & 0.19 & 0.17 & 0.02 & 0.36 & 0.17 & 115 \\
\hline $\mathrm{M} / 0.2 / 85 / 10$ & 0.19 & 0.17 & 0.02 & 0.33 & 0.14 & 107 \\
\hline $\mathrm{M} / 0.1 / 85 / 2$ & 0.20 & 0.18 & 0.02 & 0.24 & 0.04 & 25 \\
\hline $\mathrm{M} / 0.2 / 85 / 2$ & 0.21 & 0.19 & 0.02 & 0.40 & 0.19 & 133 \\
\hline $\mathrm{M} / 0.5 / 85 / 2$ & 0.17 & 0.16 & 0.01 & 0.38 & 0.21 & 125 \\
\hline $\mathrm{M} / 1.0 / 85 / 2$ & 0.03 & 0.01 & 0.02 & 0.20 & 0.17 & 97 \\
\hline
\end{tabular}

Estimated from $\alpha_{\mathrm{S}}$ method.

$V_{\text {total }}$ - volume adsorbed at $p / p^{0}=0.95$.

c $V_{\text {meso }}=V_{\text {total }}-V_{\text {micro }}$.

$5.4 \mathrm{~nm}$ corresponds always to a smaller fraction of pores and do not shift with the increase of the treatments severity. On the other hand, the maximum related to the highest fraction of pores is affected by the experimental conditions. In the example shown, the curve for the sample treated for $0.5 \mathrm{~h}$ presents a maximum at around $10 \mathrm{~nm}$, although for the samples where the treatment was prolonged for 2 or $10 \mathrm{~h}$ the maximum is shifted for pores with $12.5 \mathrm{~nm}$ diameter. So the increase of the treatment severity results not only in the increase of the mesoporores volumes but also in the formation of larger pores.

Comparing the evolution of $V_{\text {meso }}$ and $C_{\text {XRD }}$ values we observe that, with the exception of samples $M / 0.2 / 50 / 1$ and $M / 0.1 / 85 / 2$, the destruction of the zeolite framework quantified by XRD is followed by the creation of mesoporous volume. This is not a linear relation and is interesting to note that samples with identical $C_{\mathrm{XRD}}$ have different textural characteristics. This is clearly shown by the results of samples $\mathrm{M} / 0.2 / 100 / 1, \mathrm{M} / 0.2 / 85 / 4$ and $\mathrm{M} / 0.5 / 85 / 2$, that although had suffered the same loss of crystallinity $\left(C_{\mathrm{XRD}} \approx 75 \%\right)$ they all present different mesoporosity development and different microporosity decrease. The effect of each experimental parameter on the structural and textural properties seems then to be different. Actually, under the experimental conditions used, raise the treatment temperature led to the smaller mesoporosity development while increasing the base concentration allowed the larger mesoporosity enlargement (not considering sample $\mathrm{M} / 1.0 / 85 / 2$ ). The better global result in terms of crystallinity, preservation of microporosity and increase of mesoporous volume is presented by sample $\mathrm{M} / 0.2 / 85 / 2$.

\subsection{Acidity characterization}

The effect of the alkaline treatment on the acidic properties of MOR and selected desilicated samples was evaluated by the catalytic reaction of $n$-heptane cracking, which is commonly used as a model reaction to characterize the acidity of zeolites and related materials [30]. Table 3 resumes the main parameters that characterize this reaction.

For all samples, the main reaction products are hydrocarbons (olefins and paraffins) with three and four carbon atoms $\left(C_{3}+C_{4}\right)$ in percentages around $90 \%$. Light $\left(C_{1}\right.$ and $\left.C_{2}\right)$ and heavier $\left(C_{5}\right.$ and $C_{6}$ ) products are also detected with values below $2 \%$ and $8 \%$ respectively. Isomerization products are present in negligible amounts.

The evolution of total conversion with time on stream (curves not shown) exhibits an identical pattern for the parent zeolite and desilicated samples, that is, a more pronounced deactivation in the first 10 min time on stream (t.o.s.) followed by a slower deactivation until 90 min reaction, which leads to deactivation percentages above $\sim 85 \%$ for both parent and desilicated samples. The initial conversions obtained at 5 min t.o.s. (Table 3 ) show slightly higher conversions for the desilicated samples, with the exception of $\mathrm{M} / 0.5 / 85 / 2$.

Table 3

Catalytic conversion, olefin/paraffin $(O / P)$, and branched/linear $(B / L)$ ratios and deactivation percentage for $n$-heptane cracking at $350{ }^{\circ} \mathrm{C}$.

\begin{tabular}{lllll}
\hline Catalyst & Conversion $^{\mathrm{a}}(\%)$ & $O / P\left(C_{4}\right)^{\mathrm{b}}$ & $B / L\left(C_{4}\right)^{\mathrm{c}}$ & Deactivation $^{\mathrm{d}}(\%)$ \\
\hline HMOR & 31.4 & 0.3 & 2.5 & 85.3 \\
$\mathrm{M} / 0.2 / 100 / 1$ & 38.1 & 0.3 & 2.5 & 90.0 \\
$\mathrm{M} / 0.2 / 85 / 2$ & 33.7 & 0.3 & 2.6 & 87.3 \\
$\mathrm{M} / 0.2 / 85 / 10$ & 39.3 & 0.3 & 2.4 & 90.7 \\
M/0.5/85/2 & 22.9 & 0.3 & 2.6 & 83.5 \\
\hline
\end{tabular}

a Values taken at 5 min time on stream.

b Olefins to paraffins ratio calculated for compounds with four carbon atoms.

c Branched linear ratio calculated for compounds with four carbon atoms.

d Deactivation percentage calculated by the difference between the conversions values taken at 5 and 90 min time on stream, divided by the conversion obtained at $5 \mathrm{~min}$

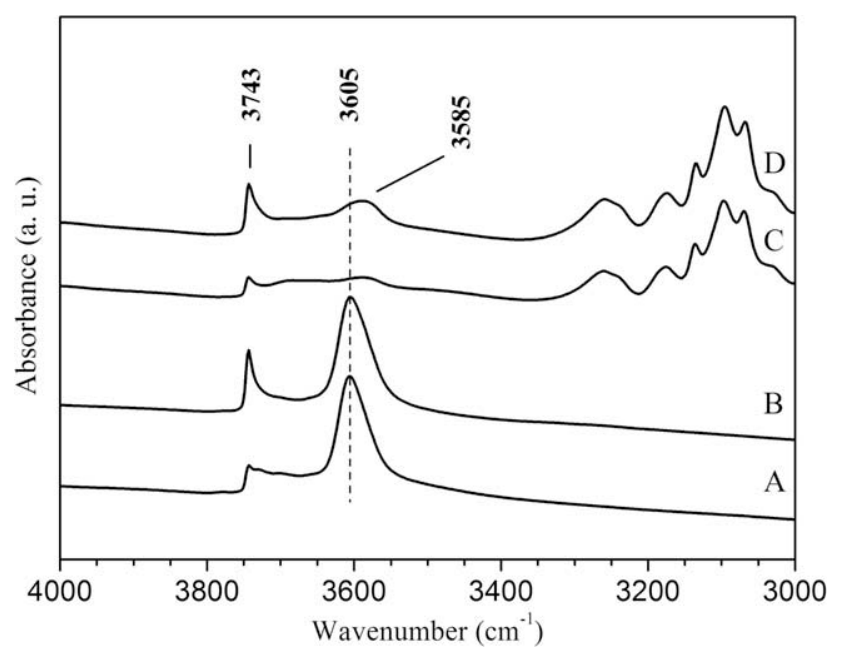

Fig. 5. Infrared spectra in the $\mathrm{OH}$ stretching region of HMOR and $\mathrm{M} / 0.2 / 85 / 2$ before $(\mathrm{A}$ and $\mathrm{B})$ and after $(\mathrm{C}$ and $\mathrm{D})$ pyridine adsorption. 
The ratio olefins/paraffins $(O / P)$ and the branched to linear ratio $(B / L)$, both quantified for products with four carbon atoms $\left(C_{4}\right)$ and for similar conversion ( $\sim 15 \%)$, are normally used to characterize the density and strength of the acid sites. The ratio $O / P$ measures the hydrogen transfer ability of the material. In this sense, as the hydrogen transfer reaction follows a bimolecular mechanism it is favoured by a high density of Brönsted acid sites [31]. On the other hand the $B / L$ ratio is related to acid strength [32]. Table 3 shows approximately the same $O / P$ and $B / L$ values both for parent and desilicated samples independently of the experimental conditions of the treatment. These results indicate that the density and strength of the acid sites remains practically unchanged after the desilication treatments.

The parent zeolite and sample $\mathrm{M} / 0.2 / 85 / 2$ were studied by infrared spectroscopy in two relevant spectral zones: the 2800$3800 \mathrm{~cm}^{-1}$ region, comprising the hydroxyl stretching modes and the $1400-1700 \mathrm{~cm}^{-1}$ region, for the pyridine ring vibrations, as a consequence of the basic molecule adsorption on Brönsted and Lewis acid sites.

Fig. 5 shows the infrared spectra of HMOR and M/0.2/85/2 samples after the outgassing treatment and before pyridine adsorption. Both spectra present two well defined bands at 3743 and $3605 \mathrm{~cm}^{-1}$, assigned to isolated silanol groups, $\mathrm{SiOH}$, and $\mathrm{Si}-\mathrm{OH}-$ Al bridging hydroxyls groups (Brönsted acid sites), respectively $[33,34]$. The second band is broad and asymmetric, suggesting the presence of at least two different acid sites, those from the main channels $\left(\sim 3605 \mathrm{~cm}^{-1}\right)$ and the others from the side pockets $\left(\sim 3585 \mathrm{~cm}^{-1}\right)$ of the MOR structure [35], even if a third band at about $3595 \mathrm{~cm}^{-1}$ (8-R opening sites) has been more recently evidenced $[36,37]$. The alkaline treated sample, when compared with the parent support, presents a more intense band corresponding to $\mathrm{SiOH}$ groups, while the band associated to the Brönsted acid sites does not change significantly upon the desilication treatment. The first observation is well in line with a subsequent increase of the external surface area as a consequence of the corrosion of crystal structure. The second observation reveals that the acidity of the
Table 4

Evolution of Brönsted and Lewis acid sites concentrations with pyridine desorption temperature for HMOR and M/0.2/85/2 desilicated sample.

\begin{tabular}{llllll}
\hline \multirow{2}{*}{ Desorption temperature $\left({ }^{\circ} \mathrm{C}\right)$} & \multicolumn{2}{l}{ Brönsted $\left(\mu \mathrm{mol} \mathrm{g}{ }^{-1}\right)$} & & \multicolumn{2}{l}{ Lewis $(\mu \mathrm{mol} \mathrm{g})$} \\
\cline { 2 - 3 } & HMOR & $\mathrm{M} / 0.2 / 85 / 2$ & & HMOR & $\mathrm{M} / 0.2 / 85 / 2$ \\
\hline 150 & 477 & 503 & 101 & 112 \\
250 & 361 & 347 & 96 & 105 \\
350 & 211 & 190 & 110 & 122 \\
450 & 56 & 44 & 132 & 130 \\
\hline
\end{tabular}

parent support is well preserved, confirming that desilication process mainly involves siliceous zones extraction while acidic $\mathrm{Si}(\mathrm{O}-$ $\mathrm{H}) \mathrm{Al}$ zones are preserved. After pyridine adsorption (spectra not shown), the bands assigned to the silanol groups remain almost unchanged for both samples, as these groups do not present an acid character. On the other hand, the main band at about $3605 \mathrm{~cm}^{-1}$ decreases significantly while the component at $3585 \mathrm{~cm}^{-1}$ (side pockets acid sites) remains intact since these groups are not accessible to pyridine molecules [35].

Fig. 6 shows the IR spectra in the $1700-1400 \mathrm{~cm}^{-1}$ region of parent zeolite HMOR and desilicated M/0.2/85/2 sample after pyridine adsorption and subsequent desorption with temperature. The spectra of both samples clearly show the bands characteristic of pyridine adsorbed on Brönsted acid sites, with the formation of pyridinium ions, $\mathrm{PyH}^{+}$, at around 1635 and $1545 \mathrm{~cm}^{-1}$, and the presence of pyridine coordinated to Lewis sites, PyL, located around 1622 and $1455 \mathrm{~cm}^{-1}$. The signal at $1490 \mathrm{~cm}^{-1}$ is common to pyridine bonded to both Brönsted and Lewis sites [38].

As the desorption temperature increases from 150 to $450{ }^{\circ} \mathrm{C}$ a decrease of the signals corresponding to pyridine adsorbed on Brönsted acid sites is observed. However, the band characteristic of Lewis acid sites remains unaffected. The removal of pyridine bonded to Brönsted sites with temperature is simultaneously accompanied by the growth of a new signal, appearing as a shoulder after desorption at $250{ }^{\circ} \mathrm{C}$, at around $1462 \mathrm{~cm}^{-1}$. Upon further
A

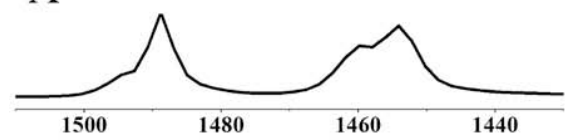

B

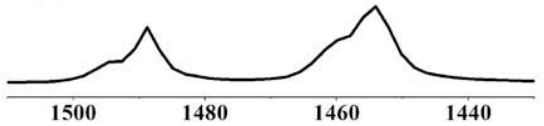

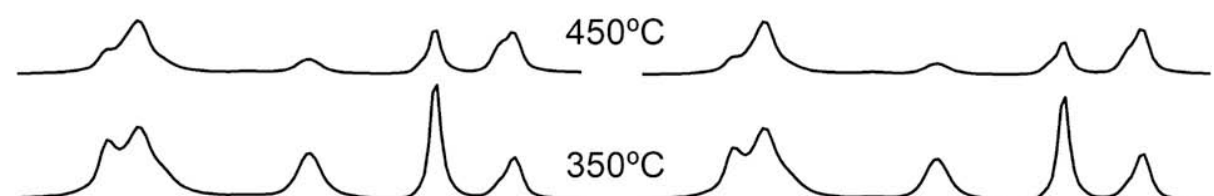

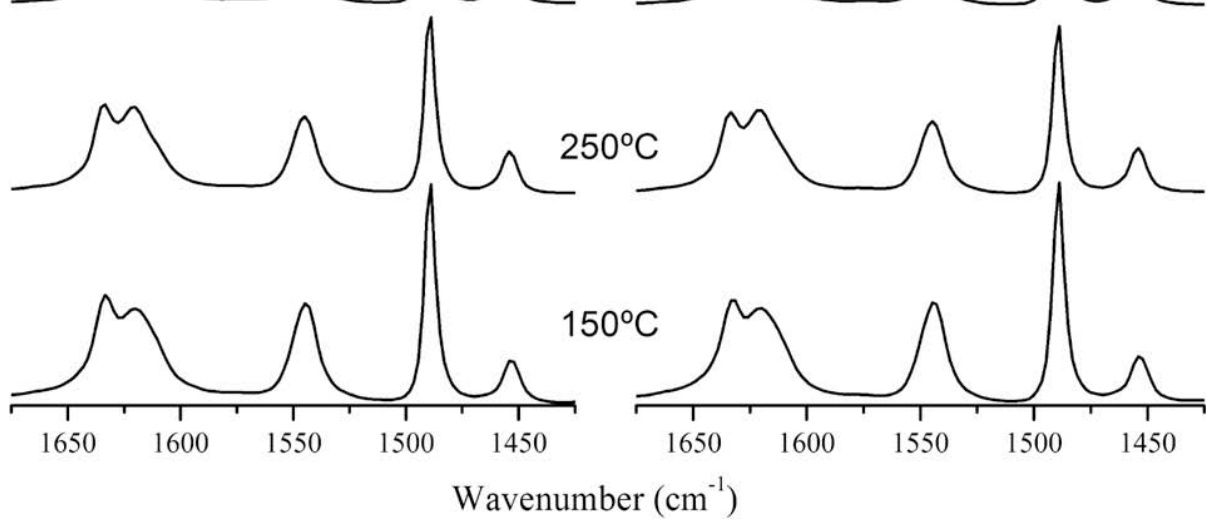

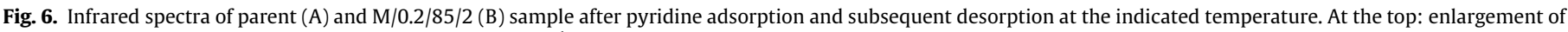
a section of the spectra for samples treated at $450{ }^{\circ} \mathrm{C}\left(2 \mathrm{~cm}^{-1}\right.$ resolution). 
desorption temperature increasing, a second new band also developed simultaneously with the first one, as a shoulder at $1500 \mathrm{~cm}^{-1}$. These new bands are clearly visible in the spectrum after pyridine desorption at $450^{\circ} \mathrm{C}$, acquired at higher resolution (see Fig. 6 , at the top). According to Chiche et al. [39] the emergence of an infrared band around $1462 \mathrm{~cm}^{-1}$ as the temperature of pyridine desorption increases can be attributed to the formation of conjugated iminium ions, which would require the presence of paired Lewis/ Brönsted acid sites. According to the reaction scheme proposed by these authors, pyridine is desorbed from a Brönsted site and coordinated to a nearby Lewis site, followed by a nucleophilic attack of the electron-deficient ring by a lattice oxygen. This dual site interaction strongly suggests the proximity of some of these two sites, as extra-framework aluminium have been detected in ${ }^{27} \mathrm{Al}$ NMR spectra in both parent and desilicated samples.

Table 4 presents the evolution of the relative acid site population for HMOR and M/0.2/85/2 samples with the increasing of pyridine desorption temperature. The concentrations of the Brönsted and Lewis acid sites were calculated from the integrated area of the $\mathrm{PyH}^{+}$and $\mathrm{PyL}$ bands using the values of the molar extinction

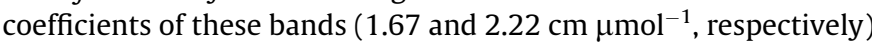
determined by Emeis [40].

Besides limitations of IR bands quantification are known and have to be considered, the analysis of Table 4 led us to compare the acid sites population in both samples. The obtained results allow us to conclude that the desilicated sample exhibit practically the same acid sites concentration for Brönsted and Lewis acid sites than the parent HMOR zeolite. This conclusion is in accordance with the results previously discussed regarding the model reaction of $n$-heptane cracking.

\section{Conclusions}

In the present work the effect of several desilication experimental parameters, such as $\mathrm{NaOH}$ concentration, temperature and time, on MOR properties was evaluated.

The alkaline treatments promoted the Si extraction from the zeolite framework, as denoted by the increase of the intensity of the line correspondent to $\mathrm{Si}(1 \mathrm{Al})$ configuration in ${ }^{29} \mathrm{Si} \mathrm{NMR} \mathrm{spec-}$ trum. The comparison of the desilication degree attained with the values of the literature is in accordance with the expected influence of the Si/Al ratio of the starting mordenite. Actually, the low $\mathrm{Si} / \mathrm{Al}$ of the sample used led to a less extensive desilication, but an important mesoporosity development was attained.

The treatments promoted loss of crystallinity (that in the majority of the cases was below 25\%), and the increase of the mesoporous structure (except when the lowest temperature $\left(50^{\circ} \mathrm{C}\right)$ and $\mathrm{NaOH}$ concentration $(0.1 \mathrm{M})$ were used $)$.

The acidity characterization proved that acidic properties of the parent material remain unchanged upon the treatment, as denoted by the results of the two techniques used: the oleffins/parafins and the branched/linear ratios remained practically unchanged as well as the site population quantified by IR bands resulting from pyridine adsorption.

The analysis of the IR spectra in the framework vibration region point out that the evolution of the asymmetric stretching band position, $v_{1}$, can be taken as an evidence of the silicon removal. The results even show that there is a linear correlation between the values of $v_{1}$ and the number of framework Si per unit cell.
As a final comment, it must be noted that, under the experimental conditions used the optimized desilication conditions are those used for the preparation of $\mathrm{M} / 0.2 / 85 / 2$.

\section{References}

[1] J.L. Figueiredo, in: J.L. Figueiredo, M.M. Pereira, J. Faria (Eds.), Catalysis from Theory to Application, Imprensa da Universidade de Coimbra, Coimbra, 2008, p. 3.

[2] S.C. Larsen, J. Phys. Chem. C 111 (2007) 18464-18474.

[3] A. Corma, M.J. Dias-Cabañas, J.L. Jordá, C. Martinez, M. Moliner, Nature 443 (2006) 842-845.

[4] A. Corma, V. Fornés, J.M. Guill, S. Pergher, T.L.M. Maesen, J.G. Buglass, Micropor. Mesopor. Mater. 38 (2000) 301-309.

[5] V. Paixão, C. Santos, R. Nunes, J.M. Silva, J. Pires, A.P. Carvalho, A. Martins, Catal. Lett. 129 (2009) 331-335.

[6] P. Matias, J.M. Lopes, P. Ayrault, S. Laforge, P. Magnoux, N.M. Guisnet, F. Ramôa Ribeiro, Appl. Catal. A: General 365 (2009) 207-213.

[7] A.N. Pinheiro, A. Valentini, J.M. Sasaki, A.C. Oliveira, Appl. Catal. A: General 355 (2009) 156-168.

[8] M.D. González, Y. Cesteros, P. Salagre, F. Medina, J.E. Sueiras, Micropor. Mesopor. Mater. 118 (2009) 341-347.

[9] M. Boveri, C. Marqués-Álvarez, M. Ángel Laborde, E. Sastre, Catal. Today 114 (2006) 217-225.

[10] M. Ogura, S. Shinomiya, J. Tateno, Y. Tateno, Y. Nara, E. Kikuchi, M. Matsukata, Chem. Lett. 8 (2000) 882-883.

[11] J.C. Groen, J.A. Moulijn, J. Pérez-Ramirez, J. Mater. Chem. 16 (2006) 2121-2131.

[12] J.C. Groen, L.A.A. Peffer, J.A. Moulijn, J. Pérez-Ramírez, Colloid. Surface. A: Physicochem. Eng. Aspect. 241 (2004) 53-58.

[13] J.C. Groen, R. Caicedo-Realpe, S. Abelló, J. Pérez-Ramirez, Mater. Lett. 63 (2009) 1037-1040.

[14] Y. Tao, H. Kanoh, K. Kaneko, Adsorption 12 (2006) 309-316.

[15] M. Guisnet, F. Ramôa Ribeiro, M. Guisnet, Les Zéolithes. Un Nanomonde au Service de la Catalyse, EDP Sciences, Les Ulis, 2006.

[16] F. Alario, M. Guisnet, in: M. Guisnet, J.-P. Gilson (Eds.), Zeolites for Cleaner Technologies, Catalytic Science Series, vol. 3, Imperial College Press, Singapore, 2002 (Chapter 4)

[17] M.M. Otten, M.J. Clayton, H.H. Lamb, J. Catal. 149 (1994) 211-222.

[18] B.T. Carvill, B.A. Lerner, B.J. Adelman, D.C. Tomazack, V.M.W. Sachtler, J. Catal. 144 (1993) 1-8.

[19] J.-K. Lee, H.-K. Rhee, Catal. Today 38 (1997) 235-242.

[20] J.C. Groen, L.A.A. Peffr, J.A. Moulijn, J. Pérez-Ramírez, Micropor. Mesopor. Mater. 69 (2004) 29-34.

[21] J.C. Groen, T. Sano, J.A. Moulijn, J. Pérez-Ramírez, J. Catal. 251 (2007) 21-27.

[22] G. Engelhardt, D. Michel, High-Resolution Solid-State NMR of Silicates and Zeolites, John Wiley \& Sons, New York, 1987.

[23] A.P. Carvalho, M. Brotas de Carvalho, F. Ramôa Ribeiro, C. Fernandez, J.B. Nagy, E. Derouane, M. Guisnet, Zeolites 13 (1993) 462-469.

[24] J.C. Groen, J.A. Moulijn, J. Pérez-Ramírez, Ind. Eng. Chem. Res. 46 (2007) $4193-$ 4201.

[25] C. Coutanceau, J.M. Silva, M.F. Alvarez, F.R. Ribeiro, M. Guisnet, J. Chim. Phys. 94 (1997) 765-781.

[26] B. Brunauer, L.S. Deming, W.E. Deming, E. Teller, J. Am. Chem. Soc. 62 (1940) 1723-1732.

[27] S.J. Greeg, K.S.W. Sing, Adsorption, Surface Area and Porosity, second ed., Academic Press, London, 1982.

[28] M. Brotas de Carvalho, A.P. Carvalho, F. Ramôa Ribeiro, A. Florentino, N.S. Gnep, M. Guisnet, Zeolites 14 (1994) 217-224.

[29] W.W. Lukens Jr., P. Schmidt-Winkel, D. Zhao, J. Feng, G.D. Stucky, Langmuir 15 (1999) 5403-5409.

[30] A. Corma, V. Fornés, J.B. Montón, A.V. Orchillés, J. Catal. 107 (1987) 288295.

[31] M.I. Poutsma, in: J.A. Rabo (Ed.), Zeolite Chemistry and Catalysis, ACS Monography 171, American Chemical Society, Washington, DC, 1976, p. 680.

[32] A. Corma, A.V. Orchillés, J. Catal. 115 (1989) 551-566.

[33] A. Zecchina, S. Bordiga, G. Spoto, D. Scarano, G. Petrini, G. Leofanti, M.J. Padovan, Chem. Soc. Faraday Trans. 88 (1992) 2959-2969.

[34] A. Zecchina, S. Bordiga, G. Spoto, L. Marchese, G. Petrini, G. Leofanti, M.J. Padovan, J. Phys. Chem. 96 (1992) 4991-4997.

[35] M. Maache, A. Janin, J.C. Lavalley, E. Benazzi, Zeolites 15 (1995) 507-516.

[36] A. Alberti, Zeolites 19 (1997) 411-415.

[37] O. Marie, F. Thibault-Starzyk, P. Massiani, J. Phys. Chem. B 108 (2004) 50735081

[38] T. Barzetti, E. Selli, D. Moscotti, L. Forni, J. Chem. Soc. Faraday Trans. 92 (1996) 1401-1407.

[39] B.H. Chiche, F. Fajula, E. Garrone, J. Catal. 146 (1994) 460-467.

[40] C.A. Emeis, J. Catal. 141 (1993) 347-354. 